\section{Consórcios de saúde: estudo de caso exitoso}

\author{
Health consortia: a case study of best practices
}

\section{Abstract}

Local Health Consortia have been used as alternatives and innovative models for improving health care provision. They are closely linked to the strategy aimed at regionalizing health care in Brazil and are in keeping with the health sector's administrative reform process, seeking greater efficiency, rationality, and quality in the supply of services to the population. In the development of such forms of cooperation, we view some consortia as weak structures with a short lifespan, while others have survived for considerable lengths of time. This case study on the Penápolis Consortium, the oldest in Brazil (having lasted for 14 years), examines the dynamics of cooperation and the reasons for its sustainability. Its formation is a mixture of restructuring the regional supply and the entrepreneurial spirit of its leaders, along with State incentives. The Consortium's local capacity to solve cases with quality care and flexible management has proven to be an important factor. Participants share the important notion that the operational rules are fair, and the reasons for its success stem from the collective perception of reasonably symmetrical political gains as the result of political cooperation.

Health Consortia; Health Planning; Health Policy
Luiz Antonio Neves 1,2

José Mendes Ribeiro ${ }^{3}$

\section{Introdução}

Os Consórcios Intermunicipais de Saúde (CIS) representam arranjos organizacionais tradicionais no setor saúde. Têm sido objeto freqüente de avaliações de resultado, impacto e mecanismos de implementação pela comunidade acadêmica. Além disso, estas soluções são debatidas no âmbito da política setorial, sendo alvo de freqüentes polêmicas. Mais recentemente, $o$ tema retornou para o centro da agenda política do setor saúde e a outras áreas como ciência, tecnologia e saneamento, como resultado de projeto governamental.

A sanção presidencial da Lei $n .11 .107$ em 6 de abril de 2005, enfatizou a importância dos consórcios como mecanismo de governança regional, favorecendo novas soluções em gestão pública, normatizando de modo inédito no país a figura do governo regional. Com isso, muitos consórcios constituídos inicialmente como entes privados iniciaram medidas para sua conversão em entes públicos.

Os objetivos principais deste artigo incluem efetuar um estudo de caso exitoso sobre o CIS mais antigo do setor saúde (em funcionamento há cerca de 18 anos) e elaborar um conjunto de recomendações, com base na experiência analisada (benchmark), para adaptações a outras experiências de CIS. 


\section{Descentralização política e consórcios de saúde no Brasil}

O processo de descentralização da política de saúde no Brasil levou a um significativo incremento das atividades e da participação dos municípios na provisão de serviços de saúde. A legislação desde a Constituição Federal de 1988, a Lei Orgânica da Saúde e as Normas Operacionais Básicas do Ministério da Saúde 1,2,3,4 definiram uma modelagem de descentralização que colocou os municípios no centro das responsabilidades pela execução dos serviços de saúde. Este tema tem ocupado o centro do debate político no setor saúde desde os primórdios da reforma sanitária até as análises sobre os problemas observados no Sistema Único de Saúde (SUS), sendo objeto de diversos enfoques 5,6,7,8,9,10,11.

Se por um lado os municípios tiveram forte influência e responsabilidade na execução dessas tarefas, os estados por sua vez experimentaram uma perda significativa de suas funções executivas e não alcançaram sua finalidade de organização de sistemas regionais hierarquizados. Além disso, a União preservou as estruturas de gestão e o quadro resultante pode ser visto no âmbito dos conflitos federativos do país na forma como tratado por especialistas no tema 12,13 .

Os CIS aparecem neste cenário como uma das alternativas de organização regional capaz de superar problemas de oferta de serviços e atenuar os aspectos competitivos do nosso federalismo. Entretanto, se claro está que os consórcios resultam em vantagens para os municípios consorciados e sua população, como apontam alguns estudos, as razões da sua indução e da sua sustentabilidade necessitam de maior investigação e são objeto comum de controvérsia $14,15,16,17,18,19,20,21,22,23,24,25,26$.

Os consórcios, em sua grande maioria, buscam superar as deficiências na assistência à saúde, notadamente na área de consultas médicas de especialidades, exames de média e alta complexidade e terapias diversas, sem estarem necessariamente subordinados ao controle do governo estadual. O menor comprometimento de governos estaduais no financiamento às políticas de saúde enfraqueceu, ao longo dos anos 90, a formação de sistemas regionais e impulsionou a solução por meio de CIS também como alternativa de financiamento, seja no custeio dos serviços ou em termos de política de investimentos.

Por outro lado, a participação dos governos estaduais se deu principalmente no apoio técnico aos municípios. As funções de cooperação técnica desenvolvidas pelas Secretarias Esta- duais de Saúde (SES) e o seu retorno recente como coordenadores regionais do SUS 27 , podem explicar os resultados de pesquisas recentes onde estas são consideradas pelos municípios como parceiras mais diretas na gestão setorial do que o próprio Ministério da Saúde, cujas funções de financiamento do setor são mais valorizadas 28 .

Neste cenário, alguns estados passaram a induzir a formação de consórcios com incentivos e financiamento de estruturas regionais voltadas para assistência de média e alta complexidade, como no caso de Minas Gerais, onde a excessiva dependência dos recursos financeiros revelou fragilidades políticas locais e comprometeu a sustentabilidade destas parcerias. Outros consórcios surgiram por percepção e escolhas políticas de lideranças locais em favor da cooperação regional, para ampliar a oferta de serviços médicos especializados. Por fim, existem consórcios, como no caso do Estado do Mato Grosso onde a participação do Governo Estadual favoreceu a sustentabilidade das parcerias locais por mecanismos de indução de uma efetiva política de regionalização, conforme demonstrado por Guimarães \& Giovanella 22.

Os consórcios favorecem estratégias de descentralização na direção de objetivos gerais do SUS para a regionalização e a hierarquização da oferta de serviços. São inovações do setor público que podem ser incluídas entre iniciativas que, embora não façam parte da agenda predominante da Reforma do Estado, geram soluções organizacionais que se afastam do modelo típico da administração direta. Favorecem a construção de sistemas regionais pactuados, respeitando o fluxo natural da demanda existente, facilitando o acesso e buscando conferir maior eficiência no uso dos serviços. Ademais, as coalizões feitas em torno dos consórcios, de uma maneira geral, têm aumentado a cooperação entre os participantes, mesmo de diferentes partidos políticos.

O Ministério da Saúde assinalou em dois importantes documentos 29,30 a relevância dos CIS como fator de integração regional de sistemas municipais. Consórcio intermunicipal está definido na legislação desde a Constituição Federal de 1937 19, com a previsão do agrupamento de municípios, dotado de personalidade jurídica, para exploração de serviços públicos em comum.

Os aspectos legais foram discutidos por Carvalho \& Santos 31, ressaltando que os consórcios intermunicipais em saúde estão previstos na Lei Orgânica da Saúde n. 8.080 de 19 de setembro de 1990 e na Lei $n .8 .142$ de 28 de dezembro de 1990. Santos 21 define os consórcios 
como acordos despersonalizados, firmados entre entidades públicas da mesma espécie ou do mesmo nível para a consecução de objetivos de interesse comum, município com município, estado com estado, autarquia com autarquia. Podem se unir para o desenvolvimento de atividades comuns ou para a implementação de programa de interesse de todos os consorciados. Destaca também as diferenças quanto à figura dos convênios, afirmando que nestes podem associar-se pessoas físicas ou jurídicas, de direito público ou privado uns com os outros, conforme o interesse de cada um. Segundo Di Pietro 32, na elaboração do consórcio é aplicável a Lei $n$. 8.666/93, que rege as licitações e contratações públicas, porém destaca, nos termos desta mesma Lei que, face às finalidades do consórcio, a exigência de licitações para a sua formação não se aplica.

Existia, entretanto, até o presente, um debate sobre a necessidade da constituição ou não de uma personalidade jurídica para a execução do consórcio. O Ministério da Saúde na cartilha O Consórcio e a Gestão Municipal 30 sugeria a formação de uma sociedade civil sem fins lucrativos para a gestão dos consórcios.

Por outro lado muitos juristas assinalavam a necessidade do comportamento administrativo dos consórcios corresponderem ao de qualquer órgão público, estando submetidos às mesmas regras como licitações e concursos, por se tratar de uma associação de órgãos públicos, gerindo dinheiro público e prestando serviço público.

A Emenda Constitucional $n .19$, de 4 de junho de 1998, que trata da Reforma Administrativa, trouxe para o plano constitucional a figura do consórcio, consolidando o pensamento associativista de muitos administradores. A edição da Lei n. 11.107 de 6 de abril de 2005, normatizou o disposto no Art. 241 da Emenda Constitucional n. 19.

A formação dos CIS teve impulso a partir de 1993, embora existam relatos de consórcios desde 1986, como na região de Conchas e o da região de Penápolis. Podemos observar um aumento crescente dessas parcerias, de um total de 109 consórcios existentes em outubro de 1997 para 143 em dezembro de 1998 envolvendo 1.748 municípios 33 . Um ponto comum entre as experiências observadas se refere às vantagens da associação e estão para além da ampliação de serviços médicos especializados, de diagnose de média e alta complexidade e de recursos terapêuticos. Os municípios envolvidos estruturam sua rede de acordo com a sua capacidade e reduzem a sua capacidade ociosa, otimizando seus serviços e a referência de pacien- tes entre municípios. Na sua relação com o setor privado observam-se efeitos regulatórios importantes na formação de preços e na ampliação do poder de barganha dos governos locais. Os resultados políticos da cooperação favorecem a sustentabilidade de muitos consórcios. Os consórcios de saúde disputam, na arena política, o protagonismo como solução organizacional e geram debates e disputas quando são apresentados para resolver problemas locais da política setorial. São duas as principais tendências para a organização de consórcios e ambas incluem a participação do governo estadual. A livre associação de municípios que se organizam segundo características políticas próprias e com uma regionalização que respeita estas mesmas características, e de outro lado, uma forte indução governamental para organizar regiões de saúde segundo as preferências do executivo estadual.

Do estudo de Lima 19, destacamos a observação de que há uma variação significativa no porcentual de municípios consorciados e a população coberta, nos estados analisados, conforme mostra a Tabela 1.

Dentre esses municípios, 95\% têm menos de 50 mil habitantes, sendo $60 \%$ com menos de 10 mil habitantes, o que sugere se tratar de um modelo de organização e de cooperação típico de cidades de pequeno porte, com vistas à superação de problemas comuns que sozinhos não conseguiriam resolver. Não há ainda no país uma única capital que pertença a consórcio, embora municípios de grande porte adotem esse tipo de associação.

Os estudos citados demonstram que de uma forma geral, os consórcios de saúde no Brasil se organizam em torno de assistência especializada, serviços de diagnose e terapia, constituindo-se como uma sociedade civil de direito privado, com sua execução seguindo regras públicas conforme já consagrado na opinião de diversos juristas. A sua estrutura decisória é centrada num Conselho de Prefeitos e a gerencial em um órgão executivo. Por outro lado, no que tange ao financiamento, observamos nos estudos existentes que municípios se cotizam para a manutenção da estrutura de funcionamento e para a provisão de serviços, ao mesmo tempo em que executam estes serviços numa base municipal recebendo transferências do SUS. A existência de um ente privado (consórcio) que executa serviços leva a uma separação da estrutura de financiamento pelos municípios envolvidos e a própria provisão pelo ente consórcio.

Mecanismos de controle sobre as suas atividades estão previstos, ora como acompanha- 
Municípios consorciados e população coberta, por Estado. Brasil, 1997.

\begin{tabular}{|c|c|c|c|c|c|c|c|}
\hline \multirow[t]{2}{*}{ Estado } & \multirow[t]{2}{*}{ Habitantes } & \multirow[t]{2}{*}{ Municípios } & \multirow[t]{2}{*}{ Consórcios } & \multicolumn{2}{|c|}{$\begin{array}{l}\text { Municípios } \\
\text { consorciados }\end{array}$} & \multicolumn{2}{|c|}{$\begin{array}{l}\text { Populaçãa } \\
\text { coberta }\end{array}$} \\
\hline & & & & $\mathrm{n}$ & $\%$ & $\mathrm{n}$ & $\%$ \\
\hline Minas Gerais & 16.673 .097 & 853 & 54 & 636 & 75,0 & 9.694 .504 & 58,0 \\
\hline Mato Grosso & 2.235 .832 & 126 & 5 & 66 & 52,0 & 961.596 & 43,0 \\
\hline Paraíba & 3.305 .616 & 223 & 1 & 10 & 4,5 & 82.618 & 2,5 \\
\hline Paraná & 9.003 .804 & 399 & 16 & 274 & 69,0 & 4.214 .947 & 47,0 \\
\hline Rio Grande do Sul & 9.637 .682 & 467 & 2 & 55 & 12,0 & 890.621 & 9,0 \\
\hline Santa Catarina & 4875.244 & 293 & 5 & 84 & 29,0 & 847.093 & 17,0 \\
\hline São Paulo & 34.120 .886 & 645 & 8 & 79 & 12,0 & 1.900 .135 & 5,6 \\
\hline Total & 79.852 .161 & 3.006 & 91 & 1.204 & 40,0 & 18.591 .514 & 23,0 \\
\hline
\end{tabular}

Fonte: Lima 19 (modificada)/Instituto Brasileiro de Geografia e Estatística (1996).

mento das próprias atividades do município via Conselho Municipal de Saúde, ora por formação de um Conselho Intermunicipal de Saúde. Diversas experiências têm se mostrado duradouras e sustentáveis, e este estudo busca analisar os mecanismos e aspectos que favorecem o êxito e as possibilidades de disseminação de soluções políticas e organizacionais adotadas. Como caso exemplar foi escolhida a experiência mais antiga e conhecida (o Consórcio Intermunicipal de Saúde da Região de Penápolis - CISA).

\section{Procedimentos metodológicos}

Foi realizado um estudo de caso sobre o CISA Penápolis para fins descritivos de experiência exitosa, caracterizada pela elevada sustentabilidade do arranjo político adotado, e para fins analíticos, de modo a definir os elementos de sucesso e os principais obstáculos ao modelo organizacional adotado pelos municípios parceiros.

Os procedimentos metodológicos adotados incluíram extensa revisão sobre a literatura científica acerca dos consórcios de saúde no Brasil, visita aos municípios e serviços de saúde, pesquisa documental (registros do CISA e das Câmaras de Vereadores de todos os municípios), pesquisa em periódicos e consultas a bases de dados administrativos. Foram realizadas ao todo dezenove entrevistas semi-estruturadas distribuídas entre todos os secretários de saúde em exercício dos municípios participantes, um dos fundadores do CISA, o então coordenador geral do CISA, três prefeitos em exercício, vereadores de três municípios e dois conselhei- ros de saúde dos municípios participantes. Foi realizado ainda um grupo focal com a participação de quatro conselheiros de saúde locais. No modelo de estudo de caso utilizado, as dimensões e variáveis analisadas foram estruturadas de modo a serem observadas em todas as dezenove entrevistas. A saturação dos temas foi assegurada pelo roteiro de entrevistas e pela atuação dos autores na qualidade de entrevistadores. As percepções e informações obtidas foram verificadas principalmente quanto à consistência por meio da consulta aos documentos obtidos e a pesquisa às bases de dados administrativas. Para a definição das questões centrais que orientaram o estudo foram consideradas a experiência dos autores, a pesquisa documental e a bibliográfica, e foram realizadas duas entrevistas de profundidade com um dos fundadores do consórcio. As principais dimensões do estudo foram a sustentabilidade do arranjo, os mecanismos de cooperação e os aspectos jurídicos e institucionais da formação e desenvolvimento da parceria na forma de um consórcio. As variáveis estudadas foram: (i) motivações para a inovação; (ii) critérios de acesso aos serviços; (iii) mecanismos de governança; (iv) elementos de êxito e ganhos políticos da cooperação; (v) mecanismos de financiamento; (vi) prestação de contas; (vii) controle do clientelismo; (viii) perspectivas da parceria.

\section{Caso Penápolis}

O estudo de caso sobre o CISA evidencia o caso exitoso do primeiro consórcio intermunicipal de saúde do Brasil, que vem funcionando regularmente há mais de 18 anos. Serviu de bench- 
mark para as demais experiências e se mantém ativo e ampliando sua oferta de serviços. Observa-se neste caso uma forte continuidade política e administrativa que sugere a permanência de um ambiente político local favorável à manutenção do consórcio, ao mesmo tempo em que o CISA, na referência feita pelos entrevistados, representa uma estrutura já consolidada e incorporada ao cotidiano dos municípios, com uma capacidade efetiva de atender as demandas dos participantes. Em que pesem estudos e descrições anteriores sobre esta experiência, em nenhum deles a ênfase foi dada aos aspectos políticos da cooperação.

A microrregião do consórcio situa-se no Noroeste do Estado de São Paulo e reúne sete municípios, sendo seis de menor porte em torno de um de maior porte. Alto Alegre (4.261 habitantes), Avanhandava (8.829), Barbosa (5.837), Braúna (4.383), Glicério (4.428), Luiziânia (4.274) e Penápolis (54.635 habitantes). Os dados populacionais referem-se ao ano 2000 e foram coletados da página da Internet do Instituto Brasileiro de Geografia e Estatística (IBGE; http:// www.ibge.gov.br). Em 1986, os municípios decidiram pela formação de um consórcio devido à experiência anterior vivida por vários prefeitos na região com outros consórcios na área de saneamento. Isto favoreceu a formação de consensos e a obtenção dos apoios necessários junto às Câmaras Municipais.

Seguindo o padrão dominante, os municípios consorciados criaram uma personalidade jurídica de caráter privado, o CISA, para administrar os recursos e coordenar as ações orientadas à oferta de atendimento médico especializado. O Conselho Fiscal foi constituído por membros indicados pelas respectivas Câmaras Municipais. É interessante verificar que a atribuição de fiscalização foi mantida com o poder legislativo, respeitando a separação dos poderes e a função precípua de cada um. Este fato favoreceu a governabilidade do CISA. Dentre suas principais atividades destacam-se as atribuições da elaboração do plano distrital e os planos municipais de saúde de cada município, e a elaboração do orçamento e de programação integrada dos serviços de saúde da região. Já havia nessa ocasião a determinação do funcionamento de conselhos de saúde e do exercício de suas prerrogativas de decisão em tais situações, mas não há registro se isto foi feito pelo Conselho de Penápolis, ou pelo de todos os municípios. Verificamos que, apesar desta determinação normativa, não houve participação consistente de conselhos de saúde no CISA. Não existe uma estrutura ou um espaço político claramente definido para a participação popular.
O CISA modificou sua estrutura incorporando outros serviços e uma unidade de controle, avaliação e auditoria comum a todos os municípios nas suas ações. Trata-se, portanto, da otimização e de economia em escala, no âmbito administrativo, onde municípios de pequeno porte podem realizar serviços dessa natureza a custo reduzido e atender às normas emanadas pelo Ministério da Saúde.

Para a efetiva consolidação dos objetivos iniciais do consórcio, de estruturação regional de um modelo de distrito sanitário, buscou-se o fortalecimento de uma estrutura de serviços primários de saúde em cada um dos municípios consorciados e uma de referência regional, de nível secundário, que foi instalada em Penápolis. Assim, desde a formação do consórcio, os municípios buscaram organizar-se localmente e os prefeitos atuavam em conjunto na busca de recursos financeiros para financiar suas estruturas. Em dezembro de 1987, foi realizado um convênio, que reflete o ineditismo do CISA, entre o Governo do Estado de São Paulo e o CIS, tendo como objeto: “...a integração no Sistema Unificado e Descentralizado de Saúde do Estado de São Paulo (SUDS-SP), dos serviços de saúde que atuam nos municípios consorciados (...) a celebração entre o Estado e o Consórcio pressupõe a integração no SUDS-SP de cada Município consorciado nos termos do Decreto no 27.140 de 30 de junho de 1997 e disposições complementares" 34 (p. 1; grifo nosso).

Com esse convênio são colocados à disposição do consórcio todos os serviços de saúde e os recursos humanos correspondentes existentes, bem como garantido o aporte de recursos financeiros para a manutenção dos mesmos pelo Governo do Estado. Esse convênio marcou, não só o ineditismo do CISA, como de fato traduziu a função mediadora que o consórcio assumiu com outras instâncias de governo.

O CISA, desde sua fundação, tem aumentado progressivamente sua oferta de serviços aos municípios. Diversas especialidades foram introduzidas para consultas e diagnose, além do fornecimento de algumas próteses e dispensação de medicamentos de sua farmácia de manipulação, revelando a capacidade em atender a finalidade para a qual foi instituído. Demonstra também a capacidade maximizadora do CISA, permitindo que municípios de pequeno porte tenham acesso a um conjunto de serviços que sozinhos não alcançariam. E, por outro lado, Penápolis que é o município pólo, deixou de ter sua rede demandada espontaneamente pela região, melhorando sua eficiência e resultados.

O financiamento do CISA é feito por meio de recursos obtidos com o faturamento de suas 
unidades próprias junto ao SUS e por cota de participação dos municípios por rateio de despesas. Representa uma importante característica deste tipo de cooperação, necessitando de alto grau de coalizão política e confiabilidade entre os participantes. Do estudo de Ribeiro \& Costa 35 , podemos verificar que a formação do consórcio não privilegiou o Município de Penápolis em detrimento dos demais em diversos aspectos. Todos os municípios estavam habilitados pela NOB/96 (sendo três em plena do sistema), quando pela NOB/93 três ainda não eram habilitados, permanecendo este quadro até março de 2000. No decorrer dos anos, todos os municípios instituíram algum tipo de ambulatório, sugerindo que o consórcio serviu como instrumento organizador/estimulador de infraestrutura de atendimento em cada município.

Em relação aos procedimentos ambulatoriais, verificamos que os municípios permaneceram em pleno desenvolvimento das suas ações e que os municípios menores vêm conseguindo manter sua base de atividades em atenção básica no próprio território. Podemos afirmar, à exceção de Braúna, que os municípios estruturaram uma oferta parcial de atividades não-básicas em virtude de uma demanda, que embora coberta pelo CISA, tem um custo operacional e político aumentado para o deslocamento da população. Isto sugere que os municípios do CISA mantêm sua capacidade operacional de atender à sua população, realizando uma reestruturação em função das necessidades apresentadas.

Verificamos na Tabela 2 que os municípios vêm mantendo uma importante utilização dos serviços oferecidos pelo CISA. A exceção é o Município de Barbosa, que reduziu significati- vamente sua utilização ao introduzir o atendimento em especialidades como ortopedia e em análises clínicas, evitando um deslocamento constante de sua população a um custo que compensou sua implementação no município. Há uma diminuição das internações de modo geral, seguindo uma tendência nacional desde que foi instituído um maior controle das fraudes e estabelecido o limite máximo de internações em $9 \%$ da população/ano, pelo Ministério da Saúde.

\section{A dinâmica política da cooperação}

As Tabelas 3 e 4 resumem e analisam os resultados obtidos por meio de entrevistas semi-estruturadas, efetuadas com os dirigentes municipais de saúde de cada um dos municípios que compõe o CISA e usuários membros do Conselho Municipal de Saúde. Foram realizadas também entrevistas com o coordenador do CISA da fase de implantação e o da ocasião do estudo, além de prefeitos. Refletem processos gerenciais observados e a percepção dos dirigentes entrevistados acerca da dinâmica da cooperação.

Na Tabela 3, podemos perceber que referente às motivações iniciais que levaram à formação do CISA, poucos dirigentes preservam a memória histórica da formação. Quanto à avaliação das regras de utilização dos serviços, todos apontaram tais regras como adequadas, realizando no próprio município atenção básica e referenciando especialidades, com agendamento por telefone. Diante de referências que o CISA não dispõe, este se responsabiliza pela busca do atendimento necessário principalmente por meio da Diretoria Regional de Saúde (DIR) de

Tabela 2

Procedimentos realizados pelos municípios. Consórcio Intermunicipal de Saúde da Região de Penápolis (CISA), 1997-2000.

\begin{tabular}{|c|c|c|c|c|c|c|c|c|}
\hline \multirow[t]{2}{*}{ Município } & \multicolumn{2}{|c|}{1997} & \multicolumn{2}{|c|}{1998} & \multicolumn{2}{|c|}{1999} & \multicolumn{2}{|c|}{2000} \\
\hline & $n$ & $\%$ & $n$ & $\%$ & $\mathrm{n}$ & $\%$ & $n$ & $\%$ \\
\hline Alto Alegre & 2.750 & 1,7 & 4.663 & 2,7 & 4.849 & 2,8 & 6.009 & 2,9 \\
\hline Avanhandava & 7.883 & 4,9 & 10.541 & 6,1 & 9.030 & 5,2 & 11.519 & 5,5 \\
\hline Barbosa & 7.378 & 4,6 & 6.234 & 3,6 & 3.002 & 1,7 & 3.680 & 1,8 \\
\hline Braúna & 6.663 & 4,2 & 6.661 & 3,9 & 7.182 & 4,1 & 7.300 & 3,5 \\
\hline Glicério & 4.431 & 2,8 & 4.349 & 2,5 & 5.363 & 3,1 & 4.178 & 2,0 \\
\hline Luiziânia & 5.216 & 3,3 & 4.751 & 2,8 & 6.122 & 3,5 & 7.135 & 3,4 \\
\hline Penápolis & 125.616 & 78,5 & 135.479 & 78,5 & 138.014 & 79,5 & 168.156 & 80,9 \\
\hline Total & 159.937 & 100,0 & 172.678 & 100,0 & 173.562 & 100,0 & 207.977 & 100,0 \\
\hline
\end{tabular}

Fonte: CISA. 
Comparativo de condutas e percepções de dirigentes sobre a dinâmica do Consórcio Intermunicipal de Saúde da Região de Penápolis (CISA), 2000.

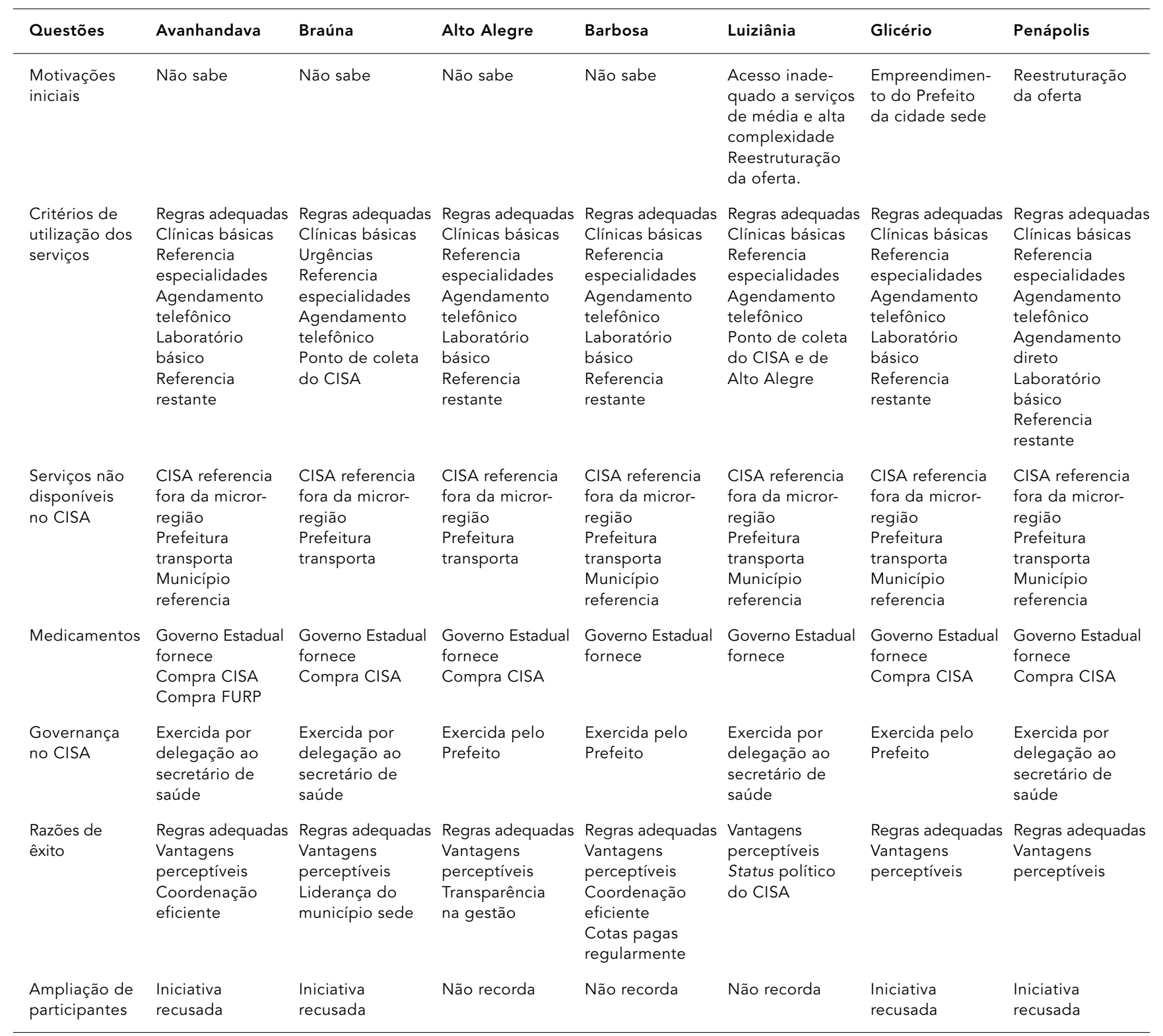

Araçatuba. Todos os municípios se responsabilizam pelo transporte de seus usuários para estas referências. Com relação à oferta de medicamentos, todos afirmam que o programa estadual se revela insuficiente para a demanda dos municípios e acabaram incorporando no CISA um laboratório de manipulação, para complementar o programa estadual, mas ainda mantendo uma lista aquém da necessidade.

Sobre a governança do CISA a maioria percebe que há poucas reuniões do Conselho de Prefeitos e de Secretários, havendo delegação das ações por parte dos Prefeitos aos seus Secretários. Estes mantêm um relacionamento mais próximo com o Coordenador do CISA. Não há na estrutura do CISA um nível de decisão dos Secretários Municipais de Saúde como também não há um órgão de participação dos usuários dos diversos municípios a exemplo de um CIS. Sobre as causas da sustentabilidade do CISA ao longo de mais de 14 anos, todos apontaram os ganhos perceptíveis da cooperação, seis incluindo as regras adequadas, três acrescentaram ainda a eficiência da Coordenação 
Percepção dos gestores sobre o Consórcio Intermunicipal de Saúde da Região de Penápolis (CISA) e de satisfação dos usuários.

\begin{tabular}{|c|c|c|c|c|c|c|c|}
\hline Questões & Avanhandava & Braúna & Alto Alegre & Barbosa & Luiziânia & Glicério & Penápolis \\
\hline Ganhos da cooperação & +++ & ++ & +++ & +++ & ++ & ++ & ++++ \\
\hline Facilidades na provisão de serviços & ++++ & ++ & ++++ & ++ & ++ & ++++ & + \\
\hline Satisfação com o sistema de cotas & ++++ & ++ & ++++ & ++ & + & ++ & ++++ \\
\hline Qualidade da prestação de contas & ++++ & ++++ & ++++ & ++++ & ++++ & ++++ & ++++ \\
\hline Favorecimento da integração entre os participantes. & + & ++++ & + & + & +++ & + & ++ \\
\hline Percepção dos usuários sobre qualidade do CISA. & +++ & ++++ & ++++ & +++ & +++ & +++ & ++++ \\
\hline Perspectivas para o CISA & +++ & ++++ & +++ & +++ & + & ++ & +++ \\
\hline Barreiras ao clientelismo político & ++++ & ++++ & +++ & +++ & +++ & +++ & ++++ \\
\hline Confiabilidade na prestação de contas & ++++ & ++++ & ++++ & ++++ & ++++ & ++++ & ++++ \\
\hline
\end{tabular}

Escala comparativa: $+/++++$.

do CISA, um à força política do CISA por sua movimentação financeira e quadro de pessoal, um à liderança do município sede e um à transparência na gestão.

Na Tabela 4, a intensidade das respostas a questões relevantes apresentadas aos entrevistados são comparadas segundo o padrão observado. Do ponto de vista das vantagens da cooperação, todos são unânimes em afirmar que houve ganhos, principalmente na referência aos serviços oferecidos, com resolutividade e melhor qualidade, e Penápolis o percebe também como reestruturação de sua oferta. Com relação às facilidades encontradas na provisão dos serviços ofertados pelo CISA, três municípios a classificam fortemente e três medianamente e somente Penápolis fracamente e que reforça seu interesse mais na reestruturação da sua demanda do que na oferta de serviços. Eventuais obstáculos parecem-nos pequenos face à oferta existente e não são estruturais ou sistêmicos, são pontuais e localizados. Sobre o sistema de cotas como rateio de parte dos custos operacionais do CISA, há forte indicação de sua aprovação em três municípios, três medianamente e um, embora concorde, acha caro. Em relação à qualidade da prestação de contas, todos apresentam alta confiabilidade. O CISA disponibiliza mensalmente um relatório de utilização dos serviços que é checado pelos municípios com a referência feita. Quanto à percepção que têm os usuários sobre a qualidade do CISA, todos acham que é boa, mas em quatro municípios ressaltam algumas pequenas reclamações. Quanto à perspectiva do CISA, todos os dirigentes acreditam na sua continuidade, apenas um limitando ao espaço temporal do período legislativo seguinte. Sobre clientelismo político no CISA, de prefeitos, vereadores, de- putados etc., três municípios afirmam que não existe e quatro não o percebem.

Os Coordenadores creditam a formação do CISA a uma reestruturação da oferta em Penápolis, pela existência de um fluxo microrregional face a serviços e ofertas de toda natureza, aliados ao componente empreendedor do então prefeito de Penápolis. Avaliaram que o CISA foi fundamental inclusive para a organização local de cada um dos municípios, na atenção básica e na consolidação da referência microrregional. Afirmaram a sustentabilidade do CISA ao longo dos anos porque atende as necessidades de referência dos municípios, os prefeitos têm noção da importância política do CISA e suas as regras são adequadas.

Os prefeitos, todos, avaliaram que o principal ganho da cooperação é o da referência com resolutividade. Da entrevista efetuada com os Conselheiros Municipais de Saúde de Penápolis todos afirmaram a dificuldade de relacionamento institucional com o CISA, por não existir um espaço legal definido. Perguntados sobre a atuação dos Conselheiros em relação ao CISA, a avaliação foi de que há pouca participação, pouca informação e uma resistência à participação deles porque são Conselheiros do Município de Penápolis e não do CISA. Com relação à percepção da qualidade dos serviços oferecidos pelo CISA, os Conselheiros avaliaram como bom o atendimento geral do consórcio.

Com relação à composição dos Poderes Legislativo e Executivo na região do CISA 36, a diversidade política é a regra observada na região de Penápolis desde a criação do consórcio em meados da década de 80 . A análise deste mosaico político sobre o qual é constituída a cooperação na política de saúde permitiu-se observar alguns sinais de sustentabilidade do ar- 
ranjo obtido. Nas Câmaras observamos que vários vereadores se reelegeram para três ou quatro mandatos, favorecendo a continuidade das políticas empreendidas. No âmbito do majoritário, em vários municípios há repetição de nomes em até quatro mandatos. Este quadro favorece também a continuidade de coalizões que sustentam o CISA. Em todas as cidades há uma certa continuidade política em mandatos seguidos, tanto nas eleições majoritárias como nas proporcionais. Isto sugere que os ganhos políticos da cooperação estejam sendo repartidos de modo aceitável pelos parceiros, o que foi assinalado pelo conjunto dos entrevistados.

\section{Considerações finais}

Verificamos no estudo 36 que os consórcios intermunicipais de saúde mantêm forte vínculo com a estratégia de regionalização da saúde no Brasil. É adequado ao processo de reforma administrativa do setor, buscando maior eficiência, racionalidade e qualidade na oferta de serviços à população. Seu aspecto inovador, como no CISA, tornou-se modelar para outras regiões que buscam, nesse tipo de estrutura, ampliar o escopo de políticas necessárias ao atendimento de suas demandas. O processo de descentralização em direção aos municípios e a necessidade da construção de modelos regionais de atenção, que pudessem atender a essas demandas, colocaram os consórcios intermunicipais de saúde como uma possibilidade concreta de regionalização.

Nesse ambiente, os consórcios encontraram condições favoráveis para se desenvolverem, sobretudo para sanar déficits do processo de regionalização na atenção à média complexidade, na oferta de consultas médicas de especialidades e em diagnose e terapia.

Nos aspectos legais vimos que a instituição da Emenda Constitucional n. 19, trouxe para o plano constitucional a figura do consórcio, consolidando esse tipo de cooperação como alternativa organizacional. Com a edição da Lei $n$. 11.107 de 6 de abril de 2005, os consórcios de saúde certamente ganham destaque, pois além da existência de várias cooperações estarem implantadas em diversas regiões do país, a previsão constitucional ficou assim legalmente estabelecida favorecendo o seu desenvolvimento. A avaliação dos consórcios de saúde no Brasil revela que $95 \%$ dos municípios envolvidos são de pequeno porte, com menos de 50 mil habitantes, o que reforça a importância desse tipo de cooperação na superação de problemas comuns. Uma lacuna importante nesta linha de investigação é a falta de um inquérito nacional sobre os consórcios.

As diretrizes do processo de regionalização, com a NOAS, preenchem algumas lacunas existentes, mesmo para o caso dos consórcios. A explicitação de responsabilidades, em nível de governo, na garantia do acesso aos serviços pela população referenciada e a transparência dos recursos financeiros destinados a essa finalidade, facilitarão as relações entre municípios, por vezes conflituosas neste nível.

O CISA Penápolis é exemplar por se sustentar há mais de 18 anos, continuar ampliando sua oferta e possuir uma boa avaliação dos municípios participantes. Ao mesmo tempo em que buscou uma reestruturação da oferta centrada na ampliação de consultas de especialidades e diagnose em média complexidade, houve a preocupação com a formação de uma rede mínima para assistência básica em cada município, inclusive Penápolis.

Chama a atenção, desde a sua formação, a inexistência de um espaço destinado à discussão e decisões por parte dos dirigentes municipais de saúde. Também existe a peculiaridade do conselho fiscal ser de representantes das Câmaras Municipais de Vereadores, órgão já definido para a fiscalização do executivo, na separação dos poderes. Entretanto, carece o CISA da participação de representantes de associações locais, embora genericamente prevista em seu estatuto e regimento interno, mas sem um mecanismo formal de participação dos diversos Conselhos Municipais de Saúde existentes. Ficou evidenciado no estudo que o CISA manteve ao longo do tempo sua capacidade operacional, com ganho em escala para os seus participantes. Ampliou sua oferta em especialidades e diagnose, e seu espectro de ação com a instituição de diversos outros serviços.

Nas entrevistas realizadas e nas observações feitas, ressalta como ponto importante da sustentabilidade do CISA a sua capacidade operacional, as regras de utilização, o rateio das despesas e o conjunto dos gastos, que são concentrados na sua atividade fim. Há uma alta confiabilidade no sistema de contas do consórcio, percepção de uma coordenação eficiente e de transparência na gestão. Chama a atenção a afirmação de todos os entrevistados da inexistência, ou não percepção, de clientelismo político no CISA.

O estudo de Teixeira et al. 37 refere como importante a possibilidade de financiamento, pelo governo estadual e/ou federal, da estrutura de consórcios aliados a mecanismos de inadimplência, para a sustentabilidade dos mesmos. Com a edição da Lei $n$. 11.104 esta possibilidade se tornou concreta. 
Como obstáculos importantes verificam-se a inexistência de uma estrutura de decisão no nível dos dirigentes municipais, de um financiamento adequado para manutenção e modernização dos serviços assistenciais, e a ausência de uma estrutura que contemple adequadamente a participação popular. No caso da atividade de associações civis, as experiências dos conselhos são contraditórias e incluem desde o seu papel como vocalizador de demandas, de ponto de sustentação de políticas, de ponto de veto ao executivo ou como agente parceiro dos governos locais 38 .

No plano político eleitoral verificamos que há ao longo do período examinado uma continuidade política, com prefeitos se mantendo na sucessão em todas as cidades, e com vereadores que se reelegeram em mandatos sucessivos, estabelecendo um ambiente político favorável à sustentabilidade do CISA. Maiorias políticas favorecem a manutenção de contratos e

\section{Resumo}

Consórcios Intermunicipais de Saúde têm sido utilizados como modelo alternativo e inovador na superação de lacunas na assistência à saúde. Mantêm forte vínculo com a estratégia de regionalização de saúde no Brasil, sendo adequados ao processo de reforma administrativa do setor, buscando maior eficiência, racionalidade e qualidade na oferta de serviços à população. No desenvolvimento dessas cooperações observamos consórcios como estruturas frágeis e de pouca duração, enquanto outros se sustentam há longo tempo. Recorremos ao estudo do Consórcio de Penápolis, o mais antigo do Brasil, que se sustenta há mais de 14 anos, para examinar a dinâmica da cooperação e procurar desvendar as razões da sua sustentabilidade. Sua formação é um misto de reestruturação da oferta regional associada ao aspecto empreendedor de seus líderes e incentivos estaduais. Sua capacidade de resolução das demandas locais, com qualidade e flexibilidade na gestão, foram importantes fatores demonstrados. Há uma importante noção entre os participantes de que as regras de funcionamento são justas e as razões para o sucesso decorrem da percepção coletiva de ganhos políticos razoavelmente simétricos como resultado da cooperação política.

Consórcios em Saúde; Planejamento em Saúde; Política de Saúde

\section{Colaboradores}

L. A. Neves realizou a elaboração do estudo, a pesquisa de campo, a análise dos resultados e a redação final. J. M. Ribeiro contribuiu na elaboração do estudo, na análise dos resultados e na redação final. neste caso observamos, além de uma expressiva manutenção de atores políticos e partidos, que os executivos têm importante base de apoio político em suas respectivas Câmaras. Embora esta questão necessite de maior investigação, neste caso, a estabilidade alcançada pelo CISA, aliada ao quadro político descrito, sugere que realmente exista um ambiente favorável à sua manutenção, ou que estas maiorias se beneficiam de alguma forma da existência do consórcio, que tem reconhecida eficiência e capacidade de atender a demanda existente. Não verificamos, em nenhum dos registros feitos, obstáculos ao CISA no quadro político partidário. Podemos afirmar que esse tipo de cooperação política, os consórcios, podem responder adequadamente às demandas regionais. E, ressalvadas as observações, se enquadrarem dentro de um modelo de organização regional com flexibilização e sustentabilidade desejável ao SUS.

\section{Referências}

1. Brasil. Constituição da República Federativa do Brasil. São Paulo: Atlas; 1988.

2. Lei n. 8080, de 19 de setembro de 1990. Dispõe sobre as condições para a promoção, proteção e recuperação da saúde, a organização e o funcionamento dos serviços correspondentes e dá outras providências. Diário Oficial da União 1990; 19 set.

3. Portaria n. 545. Estabelece normas e procedimentos reguladores do processo de descentralização da gestão das ações e serviços de saúde, através da Norma Operacional Básica, SUS 01/93. Diário Oficial da União 1993; 24 mai.

4. Portaria n. 2.203. Estabelece normas e procedimentos reguladores do processo de descentralização da gestão das ações e serviços de saúde, através da Norma Operacional Básica, SUS 01/96; Diário Oficial da União 1996; 6 nov.

5. Cordeiro H. Sistema Único de Saúde. Rio de Janeiro: Ayuri Editorial; 1991.

6. Mendes EV. Distrito sanitário: o processo social de mudança das práticas sanitárias do Sistema Único de Saúde. São Paulo: Editora Hucitec; 1994.

7. Teixeira SF, organizador. Reforma sanitária: em busca de uma teoria. 2a Ed. São Paulo: Cortez Editora/Rio de Janeiro: ABRASCO; 1995.

8. Costa NR, Silva PLB, Ribeiro JM. A descentralização do sistema de saúde no Brasil. Revista do Serviço Público 1999; 3:33-56.

9. Mendes EV. Uma agenda para a saúde. 2a Ed. São Paulo: Editora Hucitec; 1999.

10. Ribeiro JM, Costa NR. Regionalização da assistência à saúde no Brasil: os consórcios municipais no Sistema Único de Saúde (SUS). Planej Polít Públicas 2000; 22:173-220.

11. Ribeiro JM, Costa NR, Silva PLB. Inovações na gestão descentralizada de redes e organizações 
hospitalares: os casos das regiões metropolitanas do Rio de Janeiro e São Paulo. In: Negri B, Di Giovanni $\mathrm{G}$, organizadores. Brasil: radiografia da saúde. Campinas: Instituto de Economia, Universidade Estadual de Campinas; 2001. p. 555-78.

12. Abrucio LF. Os barões da federação - os governadores e a redemocratização brasileira. São Paulo: Editora Hucitec; 1998.

13. Affonso RBA, Silva PLB. A federação em perspectiva. Ensaios selecionados. São Paulo: Fundação do Desenvolvimento Administrativo; 1995.

14. Cruz MCMT. O consórcio intermunicipal de saúde da microrregião de Penápolis como instrumento de viabilização dos sistemas locais de saúde [Dissertação de Mestrado]. São Paulo: Escola de Administração de Empresas de São Paulo, Fundação Getúlio Vargas; 1992.

15. Gontijo LT, Donini O, Ribeiro JM, Cunha JPP. Sete cidades e uma história em comum. Revista Espaço para a Saúde 1994; 3:11-3.

16. Ribeiro JM. Os consórcios intermunicipais no SUS: parceria e cooperação técnica. Revista Espaço para a Saúde 1994; 3:41-2.

17. Barros PM. Consórcios intermunicipais: ferramentas para o desenvolvimento regional. São Paulo: Alfa-Omega; 1995.

18. Bastos FA, Misoczky MC. Avançando na implantação do SUS: consórcios intermunicipais de saúde. Porto Alegre: Dacasa Editora; 1998.

19. Lima APG. Os consórcios intermunicipais de saúde e o sistema único de saúde [Dissertação de Mestrado]. Rio de Janeiro: Escola Nacional de Saúde Pública, Fundação Oswaldo Cruz; 1998.

20. Lima LD. O processo de implementação de novas estruturas gestoras no Sistema Único de Saúde: um estudo das relações intergovernamentais na CIB do RJ [Dissertação de Mestrado]. Rio de Janeiro: Instituto de Medicina Social, Universidade do Estado do Rio de Janeiro; 1999.

21. Santos L. Consórcio administrativo intermunicipal: aspectos gerais, suas especificidades em relação ao Sistema Único de Saúde. Brasília: Ministério da Saúde; 2000.

22. Guimarães L, Giovanella L. Cooperação intergovernamental: os consórcios em saúde de Mato Grosso. Saúde Debate 2004; 28:149-58.

23. Ribeiro JM, Costa NR. Experiências em gestão descentralizada em redes e organizações. In: $\mathrm{Ne}-$ gri B, Di Giovanni G, organizadores. Brasil: radiografia da saúde. Campinas: Instituto de Economia, Universidade Estadual de Campinas; 2001. p. 529-54.

24. Schneider AC. Consórcios intermunicipais de saúde: instrumento de organização do sistema de saúde [Dissertação de Mestrado]. Rio de Janeiro: Instituto de Medicina Social, Universidade do Estado do Rio de Janeiro; 1998.
25. Schneider AC. Cooperação municipal? Um estudo sobre o consórcio de saúde da Região do Médio Paraíba do Rio de Janeiro [Tese de Doutorado]. Rio de Janeiro: Instituto de Medicina Social, Universidade do Estado do Rio de Janeiro; 2005.

26. Nicoletto SCS, Cordoni Jr. L, Costa NR. Consórcios Intermunicipais de Saúde: o caso do Paraná, Brasil. Cad Saúde Pública 2005; 21:29-38.

27. Portaria MS/GM n. 95. Regionalização da assistência à saúde: aprofundando a descentralização com eqüidade no acesso. Norma Operacional da Assistência à Saúde - NOAS-SUS 01/01. Diário Oficial da União 2001; 29 jan.

28. Silva PLB, Draibe SM. Avaliação da descentralização dos recursos do Ministério da Saúde para a Atenção Básica: PAB, programas e incentivos. Relatório final. Campinas: Núcleo de Estudos de Políticas Públicas, Universidade Estadual de Campinas; 2001.

29. Ministério da Saúde. O ano da saúde no Brasil. Ações e metas prioritárias. Brasília: Ministério da Saúde; 1997.

30. Ministério da Saúde. O consórcio e a gestão municipal em saúde. 1a Ed. Brasília: Ministério da Saúde; 1997.

31. Carvalho GI, Santos L. Comentários à Lei Orgânica da Saúde (Lei 8080/90 e Lei 8142/90) - Sistema Único de Saúde. 2a Ed. São Paulo: Editora Hucitec; 1995.

32. Di Pietro MSZ. Parcerias na administração pública: concessão, permissão, franquia, terceirização e outras formas. São Paulo: Atlas; 1999.

33. Ministério da Saúde. Situação dos consórcios de saúde no Brasil. http:/ /www.saude.gov.br (acessado em 12/Mar/2000).

34. Governo do Estado de São Paulo. Convênio entre a Secretaria de Estado de Saúde de São Paulo e o Consórcio Intermunicipal de Saúde de Penápolis. São Paulo: Governo do Estado de São Paulo; 1987.

35. Ribeiro JM, Costa NR. Consórcios municipais no SUS. Brasília: Instituto de Pesquisa Econômica Aplicada; 1999. (Texto para Discussão, 669).

36. Neves LAS. Consórcio intermunicipal de saúde da região de Penápolis-SP: elementos da cooperação política [Dissertação de Mestrado]. Rio de Janeiro: Escola Nacional de Saúde Pública, Fundação Osvaldo Cruz; 2001.

37. Teixeira L, MacDowell MC, Bugarin M. Incentivos em consórcios intermunicipais de saúde: uma abordagem de teoria dos contratos. Revista Brasileira de Economia 2003; 57:1.

38. Ribeiro JM. Conselhos de saúde, comissões intergestores e grupos de interesses no Sistema Único de Saúde (SUS). Cad Saúde Pública 1997; 13:81-92.

Recebido em 11/Ago/2005

Versão final reapresentada em 18/Jan/2006

Aprovado em 21/Fev/2006 